\title{
EVALUATING THE EFFECT OF FOREIGN EXCHANGE RATE AND EXCHANGE DIFFERENCES ON THE FINANCIAL STATEMENTS
}

\author{
DOI: 10.17261/Pressacademia.2018.906 \\ PAP- V.7-2018(59)-p.316-320
}

Huseyin Mert ${ }^{1}$, Didem Ozcelik ${ }^{2}$, Goktug Duyar ${ }^{3}$

${ }^{1}$ Okan University, Istanbul, Turkey.

huseyin.mert@okan.edu.tr, ORCID: 0000000153917865

${ }^{2}$ Okan University, Istanbul, Turkey.

didem-ozcelik@hotmail.com, ORCID: 0000000292733142

${ }^{3}$ Okan University, Istanbul, Turkey.

gokduyar@yahoo.com, ORCID: 0000000322464909

To cite this document

Mert, H., Ozcelik, D., Duyar, G. (2018). Evaluating the effect of foreign exchange rate and exchange differences on the financial statements. PressAcademia Procedia (PAP), V.7, p.316-320.

Permemant link to this document: $\underline{\text { http://doi.org/10.17261/Pressacademia.2018.906 }}$

Copyright: Published by PressAcademia and limited licenced re-use rights only.

\section{ABSTRACT}

Purpose- In the global world, foreign currency transactions have increased and they became a big part of balance sheet accounts. This situation brought the issue that currency exchange rate changes and their reflection on financial statements has to be considered carefully and cautiously because changes in exchange rates affect companies' assets, equity values and their profitability directly.

Methodology- In our study, following the summarization of exchange rates, current currencies and exchange rate changes and risks, we will analyze how exchange rate changes are taken into accounts and valued according to International Accounting Standards (IAS) 21.

Findings- It has been observed that TMS-21, issued in parallel with IAS-21, has led to a road map until it is reported from accounting for foreign currency transactions, and it has been observed that all businesses involved in this process are able to prevent possible disinformation in their registration and reporting process.

Conclusion- Although a healthy structure has been achieved with the TMS-21 standard in registration and reporting, foreign currency and foreign exchange-based transactions are seen to have adverse effects on the financial statements of the enterprises due to unpredictable sudden changes in the country's and global economic condition. We are convinced that certain arrangements to be made concerning the use of foreign mercenary resources will discipline such possible strains.

Keywords: Exchange rate, changes in exchange rates, exchange rate differences, the effect of foreign exchange rates, financial statements. JEL Codes: M40, M42, M49

\section{KUR FARKLARININ FINANSAL TABLOLAR ÜZERINDEKI ETKISININ DEĞERLENDIRILMESi}

\section{ÖZET}

Amaç- Globalleşen dünyada, dışa kapalı kalmak imkansız hale gelmiş olup, çok uluslu şirketler hemen hemen tüm ülkelerde faaliyet göstermeye başlamıştır. Küreselleşme ile birlikte dövize dayalı işlemler artmıştır. Yabancı paraya dayalı işlemler, bilanço kalemlerinde yadsınamaz bir hacimde yer almaktadır. Hacimsel olarak finansal tablolar üzerindeki bu etki, döviz kurlarında, artış-azalış gibi, değişimlerle, finansal raporlamada dikkat ve önemle ele alınması gerekliliğini öne çıkarmaktadır. Döviz kurlarındaki değişimler, dövize dayalı işlemleri olan işletmelerin, çok uluslu şirketlerin vb., bilançolarındaki varlık ve kaynaklarının değerlerine ve karlılığın tespitine direkt etki etmektedir. Yöntem- Çalışmamız, döviz kuru, geçerli para birimi, kur değişimleri ve risklerine ait genel bilgiler geçişiyle döviz kurlarındaki değişimlerin uluslararası standartlara paralel ulusal bir standart kapsamında muhasebeleştirilip değerlemesinin yapılması üzerinden hareket edilmiştir. Bulgular- IAS-21'e paralel olarak düzenlenmiş TMS -21'in yabancı paralı işlemlerin muhasebeleştirilmesinden raporlanmasına kadar bir yol haritası çıkardığı ve bu haliyle ilgili tüm işletmelerin kayıt düzeni ve raporlama süreçlerinde yaşayacakları olası dezenformasyonun önüne geçmesinin sağlandığı gözlemlenmiştir.

Sonuç- Her ne kadar TMS-21 standardı ile kayıt düzeninde ve raporlamada sağııkı bir yapıya kavuşulmuş olsa da gerek ülke ekonomik koşullarından gerekse global ekonomik koşullarındaki öngörülemeyen ani değişimlerden dolayı yabancı para ve yabancı paraya dayalı işlemlerin işletmelerin finansal tablolarına olumsuz etkilerinin olduğu görülmektedir. Yabancı paralı kaynakların kullanımlarıyla ilgili getirilecek birtakım düzenlemelerle, söz konusu olası sıkıntıların disiplin altına alınacağı kanaatindeyiz.

Anahtar Kelimeler: Kur, kur farkı, kur farkı değişimleri, kur farkı etkileri, finansal tablolar.

JEL Kodları: M40, M42, M49 


\section{GíRiş}

Dışa açık ekonomilerde işletmelerin uluslararası ticaretin dışında kalmaları pek mümkün gözükmemektedir. KOBí'leri de içine alan bu süreçte artık işletmeler bilançolarında aktif ve pasiflerinde yer alan bazı unsurları ve bunun yanında nakit akışlarını yabancı para cinsinden de izlemektedirler; dolayısıyla bu durum işletmelerin, finansal tablolaları üzerinde yabancı paralı işlemlerin nicelik olarak artmasına ve bu artışla da finansal tablolarda bulunan diğer unsurlarla birlikte tüm bu kalemlerin aynı para cinsinden gösterilmesi gerekliliği kapsamında yabancı para ile yapılan her türlü işlem ve bu işlemlere ait muhasebe kayıtlarının tek bir para cinsine çevirilmesi ve raporlarda gösterilmesi gerekmektedir.

Bir işletme; yabancı para birimlerinde işlemler yapmak ya da yurtdışında işletmeye sahip olmak suretiyle yabancı faaliyetlerde bulunabilir. Ayrıca, bir işletme finansal tablolarını bir yabancı para biriminde sunabilir. Bu standardın amacı, yabancı para işlemlerin ve yurtdışındaki işletmelerin finansal tablolara nasıl dahil edileceğini ve finansal tablolarda kullanılan para birimine nasıl çevrileceğini düzenlemektir. Hangi döviz kuru/kurlarının kullanılacağı ve döviz kurlarındaki değişimin finansal tablolar üzerindeki etkilerinin nasıl raporlanacağı bu standardın temel konularıdır. ${ }^{1}$ Amacıyla düzenlenen TMS 21 standardı Uluslararası Denetim Standardı (IAS. 21) ile uyumlu hale getirilerek, ülkemizde de kur değişimlerinin etkileri bir standarda bağlanmıştır.

Biz de bu çalışmamızla TMS 21 kapsamında döviz ve dövize dayalı işlemlerin ilk muhasebeleştirilmesi, finansal tablolara aktarılması ve sunulması sürecine kadar olan aşamalara değinerek, döviz ve döviz kurundaki değişimler ve döviz kuru riskinin finansal tablolar üzerindeki etkilerinin neler olabileceğine dair bilgiler sunmayı amaçlamaktayız.

\section{KUR FARKLARININ FINANSAL TABLOLAR ÜZERINDEKI ETKISININ DEĞERLENDIRILMESi VE ÖRNEKLERLE ANALIZI VE YORUMLANMASI}

\section{1. TMS 21 Kur Değişimi Etkileri Standardının Amacı ve Kapsamı}

TMS-21 Kur Değişiminin etkileri Standardının amacı yabancı para işlemlerin ve yurtdışındaki işletmelerin finansal tablolara nasıl dahil edileceğini ve finansal tablolarda kullanılan para birimine nasıl çevrileceğini düzenlemektir (www.gureli.com.tr, 2018).

Kur, iki milli para arasındaki değişim oranıdır. Diğer bir ifade ile yabancı paranın milli para cinsinden fiyatıdır (Karluk, 2007). Kur farkı ise, belli bir miktar yabancı para biriminin yerel para birimi ile değiştirilmesi sırasında oluşan alış ve satış kurları arasındaki farktır (Apak, 2018).

Döviz kuru değişim etkilerinin muhasebeleştirilmesi ve bu etkilerin finansal tablolarda gösterimi konularında IASB tarafından çıkarılan IAS 21 Kur Değişim Etkilerinin Muhasebeleştirilmesi (İngilizce: The Effects of Changes in Foreign Exchange Rates) konulu ilk kez 1983 yılında yayınlanmış, ancak ekonomik yaşamda ortaya çıkan gelişmeler göz önünde tutularak 1993 yılında yeniden yayınlanmıştır (Çatıkkaş ve Çalış, 2008). 1993 yılında yayınlanan standartta 1998, 2000 ve 2001 yıllarında dört yorum (Ingilizce: Interpretations) yayınlanmıştır (www.iasplus.com, 2018). 2003 yılında revize edilen bu standartta diğer standartlardaki değişikliklerle paralel güncellemeler yapılmaya devam edilmektedir (International Financial Reporting Standards, 2008).

Bir işletme; yabancı para birimlerinde işlemler yapmak ya da yurtdışında işletmeye sahip olmak suretiyle yabancı faaliyetlerde bulunabilir. Ayrıca, bir işletme finansal tablolarını bir yabancı para biriminde sunabilir. Bu Standardın amacı, yabancı para işlemlerin ve yurtdışındaki işletmelerin finansal tablolara nasıl dahil edileceğini ve finansal tablolarda kullanılan para birimine nasıl çevrileceğini düzenlemektir. Hangi döviz kuru/kurlarının kullanılacağı ve döviz kurlarındaki değişimin finansal tablolar üzerindeki etkilerinin nasıl raporlanacağı bu standardın temel konularıdır (http://kgk.gov.tr, 2018).

\section{2. Geçerli Para Birimi}

Finansal tabloları düzenlerken, aynı türden para birimi üzerinden hazırlanması gerekliliğini göz önünde bulundurulmalı ve bu doğrultuda, işletmelerin geçerli para birimini belirleyip, finansal tabloları düzenlemelidirler. TMS $21^{\prime}$ de "geçerli para birimi", işletmenin faaliyet gösterdiği temel ekonomik çevrenin para birimi olarak tanımlanmaktadır. Başka bir ifadeyle TMS-21 Kur Değişiminin etkileri standardına göre geçerli para birimi, doğrudan o ülkenin resmi parasıdır. Geçerli para biriminin belirlenmesi bir seçim olmaktan ziyade doğru raporlama yapılabilmesi için gerekli bir parametredir. Keza genel anlamıyla nakit giriş ve nakit çıkışların yapıldığı para birimi olarak da söylenilebilir. Işletmenin faaliyette bulunduğu sektörde şartların radikal değişimiyle geçerli para birimi de değişiklik gösterebilir yani değişebilir. Geçerli para birimine, fonksiyonel para birimi olarak da görebiliriz.

\section{3. Parasal Kalemler}

TMS 21 kur farklarının belirlenmesi ve muhasebeleştirilmesinde kalemler için parasal ve parasal olmayan ayrımına girmiştir. Parasal kalemler, elde tutulan para ile sabit veya belirlenebilir bir tutarda para olarak alınacak veya ödenecek varlık ve borçlar olarak tanımlanırken, belirli bir tutarda para olarak alınamayacak veya ödenmeyecek varlık ve borçlar ise parasal olmayan kalem olarak değerlendirilmektedir (Gürsoy, 2016).

\section{4. Yurtdışındaki İşletmede Bulunan Net Yatırım}

Yurtdışındaki işletmenin faaliyet sonuçlarının ve finansal durumunun, raporlayan işletmenin finansal tablolarına konsolidasyon, oransal konsolidasyon ya da özkaynak yöntemi ile dahil olabilmesi için, finansal tablolarda kullanılan para birimine çevrilmesinde uygulanır (www.resmigazete.gov.tr, 2018).

${ }^{1}$ http://www.resmigazete.gov.tr/eskiler/2005/12/20051231-52.htm 


\section{5. ilk Muhasebeleştirme}

Yabancı para işlemleri, yabancı para ile fonksiyonel para birimi arasındaki işlem tarihindeki spot kur uygulanmak suretiyle bulunan tutar üzerinden fonksiyonel para birimi cinsinden kayıtlara alınır. İşlem tarihi, ilgili kalemin mali tablolara alınmasının gerekli olduğu ilk tarihtir (https://ufrsturk.wordpress.com2018)

Yabancı para bir işlem, yabancı para biriminde gerçekleştirilmiş ya da ödemenin yabancı para biriminde gerçekleştirilmesini gerektiren bir işlem olup, aşağıdakileri de kapsar:

- İşletmenin, fiyatları yabancı bir para biriminde belirlenen mal ve hizmetleri alıp satması;

- İşletmenin, borç ya da alacak tutarları yabancı bir para biriminde belirlenen kredi alması ya da borç vermesi;

- Işsletmenin, yabancı bir para birimi cinsinden varlık iktisap etmesi ya da elden çıkarması ile bu tür yükümlülüklerin doğması veya ifa edilmesi.

Uygulama kolaylığı nedeniyle, işlem tarihindeki gerçek kura yaklaşan bir kurun, örneğin, haftanın ya da ayın ortalama kurunun, o dönem içinde her bir yabancı para biriminde gerçekleşen işlemlerin tümü için kullanılması mümkündür. Bununla birlikte, döviz kurunun önemli ölçüde dalgalanması durumunda dönem için ortalama kur kullanılmaz (http://www.resmigazete.gov.tr).

\section{6. İzleyen Raporlama Dönemi Sonunda Raporlama}

Raporlama döneminin sonu itibariyle yabancı paralı işlemlerin hangi kurdan çevrileceği aşağıdaki hususlara bağlıdır:

- Muhasebe kaleminin parasal olup olmadığına

- Parasal olmayan kalemlerin tarihi maliyetle mi yoksa gerçeğe uygun değeri zerinden mi ölçüldüğüne.

\subsubsection{Parasal Kalemlerin Raporlanması}

Her raporlama dönemi sonunda yabancı paralı parasal kalemler kapanış kurundan, diğer bir ifadeyle dönem sonundaki spot kurdan, çevrilir. Parasal kalemli işlemler (örnek olarak krediler ya da alacaklar) raporlama tarihi itibariyle ödenmiş (tahsil edilmiş) ya da ödenmemiş (tahsil edilmemiş) olabilir. Raporlama tarihinden önce ödenen (tahsil edilen) parasal kalemler işlemin yapıldığı tarihteki spot kur kullanarak çevrilir. Raporlama tarihinde ödenmemiş (tahsil edilmemiş) parasal kalemler ise, finansal durum tablosu an itibariyle işletmenin finansal durumunu yansıttı̆̆ı için, kapanış kurundan çevrilir.

TMS 21, oluşan kur farklarının kâr veya zarar tablosu içinde nasıl belirtileceği konusunda bir yer işaret etmemiştir. Ama raporlama yapılırken, işletme faaliyetleri kapsamında oluşan kur farkları "İ̧̧letme Faaliyetlerinden Gelirler ve Giderler" ana başlığının altında; diğer yandan finansman faaliyetleri yani döviz cinsinden ya da dövize endeksli kullanılan yabancı kaynaklardan oluşan kur farkları da "Finansman Faaliyetlerinden Gelir ve Giderler" ana başlığı altında gösterilir.

\subsubsection{Parasal Olmayan Kalemlerin Raporlanması}

Parasal olamayan kalemler, ilk muhasebeleştirildikleri tarihteki işlem (spot) döviz kuru üzerinden çevrim yapılarak finansal raporlarda yerini alır. Dolayısıyla dönem sonlarında parasal olmayan kalemler için yeniden çevrim işlemi yapılmaz.

\subsubsection{Parasal Kalemlere İlişkin Kur Farkları}

Bilindiği gibi parasal kalemler elde tutulan para ile sabit veya belirlenebilir bir tutarda para olarak alınacak veya ödenecek varlık ya da borçlar olarak tanımlanır. Ancak, tüm finansal varlıklar parasal kalemler olarak değerlendirilmez. Örneğin, özkaynaklara dayalı finansal araçlar parasal kalem değildir. Çünkü bu varlıklar sabit veya belirlenebilir tutarda para olarak geri alınamazlar.

\subsection{Kur Farklarının Muhasebeleştirilmesi}

TMS 21, yabancı para birimine dayalı işlemlerden kaynaklanan kur farklarının muhasebeleştirilmesinden kaynaklanan kazanç ya da zarar diğer kapsamlı gelirde muhasebeleştiriliyorsa aynı şekilde bu kazanç ya da zararın kurdan kaynaklanan kısmı da diğer kapsamlı gelirde muhasebeleştirilir. Buna karşın, parasal olmayan bir kalemden kaynaklanan kazanç ya da zarar, kâr ya da zararda muhasebeleştirilirse, bu kazanç ya da zararın kurdan kaynaklanan kısmı da kâr ya da zararda muhasebeleştirilir. Kaynaklanan kazanç ya da zarar diğer kapsamlı gelirde muhasebeleştiriliyorsa aynı şekilde bu kazanç ya da zararın kurdan kaynaklanan kısmı da diğer kapsamlı gelirde muhasebeleştirilir. Buna karşın, parasal olmayan bir kalemden kaynaklanan kazanç ya da zarar, kâr ya da zararda muhasebeleştirilirse, bu kazanç ya da zararın kurdan kaynaklanan kısmı da kâr ya da zararda muhasebeleştirilir. 
Tablo 1: Parasal/Parasal Olmayan Kalemler

\begin{tabular}{|l|l|}
\hline Parasal Kalemler & Parasal Olmayan Kalemler \\
\hline Nakit & Maddi Duran Varlıklar \\
\hline Banka Hesapları ve Kredileri & Maddi Olmayan Duran Varlıklar \\
\hline Teminatlar & Şerefiye \\
\hline Kıdem Tazminatı Karşılıklar & Sermaye \\
\hline Gider Tahakkukları & Peşin Ödenen Giderler \\
\hline Satıcılar & Ortaklara Yapılan Yatırımlar \\
\hline Ödenecek / Indirilecek Vergi & Stoklar \\
\hline Borçlanma Senetleri & Stok Değer Düşüklüğü Karşılığı \\
\hline Ticari Alacaklar & Gelecek Yıllara Ait Gelirler \\
\hline Şüpheli Ticari Alacak Karşılığı & Hisse Senetleri \\
\hline Alacak Senetleri ve Diğer Alacaklar & Parasal Olmayan Varlık Karşılıkları \\
\hline Borç Senetleri ve Diğer Borçlar & \\
\hline Gelir Tahakkuklar & \\
\hline Ertelenmiş Vergi Varlığı/Yükümlülüğü & \\
\hline Finansal Kiralama Ödemeleri & \\
\hline Kaynak: Hall, N,; Barden, P. ve Poole, V. 2014.Deloitte iGAAP Volume A Part 2. Lexis Nexis. London: 1546.
\end{tabular}

Kaynak: Hall, N.; Barden, P. ve Poole, V. 2014. Deloitte iGAAP Volume A Part 2. Lexis Nexis. London: 1546.

\section{SONUÇ}

Uluslararası faaliyetlerde bulunan işletmeler ve bunun dışında olup kendi ülkelerinde kendi ulusal para birimleriyle faaliyetlerine devam etmekte olan ama know-how, teknoloji yatırımı, hammadde alımı, lisans, patent, isim hakkı, danışmanlık gibi birtakım girdileri sağlamak adına, dövize dayalı işlemlerle yapan işletmeler, yurt içinde dahi olsa döviz üzerinden yada dövize endeksli bazı ihaleler ve kamunun geliştirdiği birtakım yeni finansman modellerine dahil olan işletmeler dövize dayalı işlemlerle karşı karşıya kalmakta ve bu durum haliyle finansal tablolarına da etki etmektedir

Bunun yanında ülkelerin uyguladığı kur politikaları sonucunda ülkeye yabancı para girişi hızlanıyorsa özellikle reel sektör başta olmak üzere işletmeler döviz cinsinden yada dövize endeksli kredilere yönelerek TMS-21 kapsamına dahil olmaktadırlar. Bundan dolayıdır ki bu tür işletmeler, yabancı yatırımları, sermaye yapısında yabancı ortaklık oluşu ve buna bağlı olarak kendisinin diğer ortaklara göre farklı para birimi kullanmaları, kısa-orta ve uzun vadede yabancı kaynak sağlamaları, yurt içinde alınan döviz yada dövize endeksli ihaleler ve benzeri kamu finansman modellerine dahil olmaları sebebiyle finansal tablolarını yabancı para biriminden kendi para birimine çevirimini yaparak düzenlemeleri gerekmektedir.

Yabancı para üzerinden işlemlerin yapılması ve bu işlemlerin sonuçlarının, kur farklarındaki değişimler doğrultusunda, belirlenen standartlara uygun olarak finansal tablolara değerlemelerinin yapılıp aktarılmasıyla, işletmelerin kar zarar durumlarının tespiti ve bunların vergilendirilmesinin önemi ortaya çıkmaktadır.

Sığ ekonomilerde, işletmelerden başlayıp sektöre varan yayılımıyla kur farklarındaki dalgalanmaların, sık değişimlerin olumsuz sonuçları, işletmeleri, devamında sektörü ve makro düzeyde de ülke ekonomisini A'dan Z'ye olumsuz etkileyip, dışa bağımlı hale getirip borç sarmalına sürükleyebilir.

Geçici ekonomik ve popülist çözüm paketlerinde uygulanan para politikalarında, ülkeye sıcak para çekmek amacıyla, baskılı döviz politikası uygulandığında, oluşan yabancı para arzının artışıyla, bu politikadan etkilenip kısa vadede kurtuluş görüp dar bir bakış açısıyla, işletmeler dövize yöneliyor ve yabancı kaynak arayışını döviz cinsinden ya da dövize endeksli kredilerle 1-5 yıl gibi vadelerle giderme yolunu seçmesiyle, kur farklarındaki değişimlerin yaratacağı sıkıntılara kapılarını aralamış oluyorlar. Bu durum bilançolarının pasif tarafını da dövize dayalı yapıyor, ancak buna karşılık bilançolarının aktif tarafındaki varlıkları döviz cinsinden değerleyemediğinden ötürü, gelirleri TL, kaynakları döviz cinsinden olunca firma devamlı surette açık pozisyonda kalıyor. Sürekliliği daima risk altında olan bu tür bir işletmenin bilançolarının da sağlıklı ve gerçekçi olduğundan söz etmek mümkün olmamaktadır. Mali idarenin uyguladığı, baskılı döviz politikalarının etkileriyle, mali sektörün, reel sektörü dövizle fonlama istekleri arttırır bir hal alması sonucunda reel sektör, kurlardaki dengesiz değişimlerin olumsuz etkileriyle, dar boğaza sürüklemeleri de kaçınılmaz oluyor.

Girdilerin finansmanı döviz cinsinden ya da dövize endeksli kredilerle yapılmasıyla artan dövize dayalı borç yükünün, ihracattaki artış aynı oranda olmaması, örneğin dövize dayalı borç 4 artarken ihracat 1 artıyorsa, yani sadece döviz borcunda bir artış söz konusuysa, mali sektör, bankacılık kanalıyla dövize dayalı fonlama seçimi ve isteğiyle verdikleri bu tür kredilerin geri dönüş riskini arttırdığı gibi sermaye yeterlilik rasyosunun negatif yönlü bozulmasına sebep oluyor.

Kamu ihaleleri, özelleştirme, hasılat paylaşımı, yap-işlet - devret gibi kamunun geliştirdiği finansman modellerini, döviz cinsi ya da dövize endeksli olarak gerçekleştirmeleriyle, bu işlere girişimci olarak dahil olan büyük ölçekli firmaların, dolarizasyon sarmalının içine girip açık pozisyonda kalmalarına ve ciddi sıkıntılar yaşamalarına sebep oldukları gözlemlenmektedir. Bu yönleriyle ele aldığımızda, girdilerin dövizle olup, çıktıların yurt içinde TL üzerinden satılması/hizmet sunulması, ekonomiyi genel anlamıyla ciddi sıkıntılara sokmasına neden olduğu net bir şekilde söylenebilir.

Bu sıkıntıları aşmak üstesinden gelmek adına işletmelerin mali tablolarında birtakım düzeltmelere gitmeleri ihtiyacı hasıl olmaktadır. Bunun için de mali mevzuatta yapılacak değişiklikler ve yeniliklerle döviz cinsi yada dövize endeksli borçlanmalarda oluşan kur farklarının tamamının, cari yıl içinde değil de amortisman uygulamasındaki gibi gelecek yıllara sarkan döviz cinsi borçlara dayalı oluşacak kredilerin, ödeme dönemlerinde ortaya çıkacak kur farklarının gider olarak yazılmasına imkan vermek; döviz cinsinden ve dövize endeksli kredileri 
sadece yatıım kredileri ile sınırlandırmak çok daha sağlıklı olacaktır ki böylelikle fiktif olmayan bir durumun finansal tablolarda yer almasına mani olunarak fiktif olan bu zarar kayıtlarının yarattığı belirsizler ve tereddütler bir şekilde bertaraf edilmiş olur; diğer taraftan da döviz cinsi yada dövize dayalı satın alma ve işletme kredileri kullanımının önüne geçilmesiyle girdi çıktı dengesinde, girdi maliyetlerinin de TL üzerinden olması, bu dengeyi sağlayıcı bir hamle olacağı görüşündeyiz.

\section{KAYNAKÇA}

Apak, T. (2018). YMM, mal veya hizmet teslimine bağlı olarak lehe veya aleyhe oluşan kur farkının KDV açısından değerlendirilmesi. www.alomaliye.com 19.01.2018

Çatıkkaş, Ö., Çalış, Y. E. (2008). Kur değişimi etkilerinin Türkiye muhasebe standardına göre muhasebeleştirilmesi ilkeleri. E-Yaklaşım, Sayı.56, Mart 2008, www.yaklaşım.com.tr, 04.10.2008.

Çetin, Ş. (2014). Yabancı para ile yapılan işlemlerde oluşan kur farklarının muhasebeleştirilmesi.

http://archive.ismmmo.org.tr/docs/malicozum/125malicozum/014_S\%C4\%9Fenol_C\%C4\%9Fetin_.pdf, 06.02.2018.

Gürsoy, A. (2016). Kur farklarının finansal tablolar üzerindeki etkilerinin belirlenmesi. http://denetimakademisi.com/wpcontent/uploads/2017/08/KUR-FARKLARININ-F\%C4\%BONANSAL-TABLOLAR.pdf, 06.02.2018.

Rekabet Kurumu. (2017). Türkiye muhasebe standartları.

http://kgk.gov.tr/Portalv2Uploads/files/DynamicContentFiles/T\%C3\%BCrkiye\%20Muhasebe\%20Stand artlar\%C4\%B1/TMSTFRS2011Seti/TMS21.pdf, 19.01.2018.

Bülent, K. (2017). TMS-21 kur değişiminin etkileri standardı kapsamında finansal tabloların çevrimi. http://www.gureli.com.tr/vk/makaleler/denetim-makaleleri/tms-21-kur-degisiminin-etkileri-standardi-kapsaminda-finansal-tablolarincevrimi,19.01.2018

http://www.iasplus.com/standard/ias21.htm\#0511amend ,10.01.2018.

Resmi Gazete. (2005). Kur değişiminin etkilerine ilişkin Türkiye muhasebe standardı (TMS21) hakkında tebliğ. http://www.resmigazete.gov.tr/eskiler/2005/12/20051231-52.htm, 19.01.2018.

https://ufrsturk.wordpress.com/tag/parasal-kalemler/,19.01.2018.

International Financial Reporting Standards (IFRSs) (2008). İngiltere: International Accounting Standards Committee Foundation (IASCF). Karluk, R. (2007). Uluslararası ekonomi, teori ve politika. Beta Bas. 